Área Abierta. Revista de comunicación

audiovisual y publicitaria

ISSN: 2530-7592 / ISSNe: 1578-8393

\title{
Juez Dredd y eugenesia: selección artificial, control social y tecnología en una distopía cinematográfica
}

\author{
José Manuel Caro Gavilán ${ }^{1}$
}

Recibido: 21 de diciembre de 2017 / Aceptado: 24 de marzo de 2019

Resumen.La eugenesia decimonónica y de principios del siglo XX, influenciada por el degeneracionismo, alegaba una degradación de los individuos de la sociedad con la intención de apelar a la responsabilidad estatal para llevar a cabo prácticas que evitarían la degeneración de la población e incluso la mejorarían cualitativamente. El objetivo de este artículo es analizar, usando la metodología neohistoricista, estas ideas decimonónicas recogidas en el discurso ideológico del relato cinematográfico de finales del siglo $\mathrm{XX}$, Juez Dredd. Así, el Estado de este relato distópico, filmado en un contexto histórico conservador y en crisis, utiliza el control social, la selección artificial y la tecnología como mecanismos para afianzar y perpetuar la estructura política y social

Palabras clave: Eugenesia; distopía; selección artificial; control social; tecnología; degeneracionismo; cine.

\section{[en] Judge Dredd and Eugenics: Artificial Selection, Social Control and Technology in a Cinematographic Dystopia}

\begin{abstract}
Eugenics in the late nineteenth and early twentieth centuries, influenced by social degeneration theory, alleged a degradation of the individuals in society in a way that sought to appeal to the State's responsibility to carry out practices that would avoid the degeneration of the population and even improve it qualitatively. The objective of this article is to analyze, using neohistoricist methodology, these conservative nineteenth-century ideas collected in the ideological discourse of the late twentiethcentury film narrative, Judge Dredd. Thus, the State in this dystopian narrative, filmed in a conservative and crisis historical context, uses social control, artificial selection and technology as mechanisms to strengthen and perpetuate the social and political structure.
\end{abstract}

Keywords: Eugenics; dystopia; artificial selection; social control; technology; Degenerationism; cinema.

Cómo citar: Caro Gavilán, J.M. (2019) Juez Dredd y eugenesia: selección artificial, control social y tecnología en una distopía cinematográfica, en Área Abierta. Revista de comunicación audiovisual y publicitaria 19 (2), 221-235. http://dx.doi.org/10.5209/ARAB.58489

La distopía cinematográfica fue un tipo de relato residual para la industria de la cultura popular de masas de Hollywood hasta finales del siglo XX. Desde la década de los años ochenta, los relatos distópicos comenzaron a tener una mayor presencia entre las películas producidas cada año por la industria cinematográfica estadounidense, de manera que siguieron siendo un tipo de relato habitual, al menos, hasta principios del siglo XXI. Este trabajo de investigación pretende analizar el relato

\footnotetext{
$1 \quad$ Universidad de Cádiz (España)

E-mail: jm.caro.gavilan@gmail.com
} 
distópico hollywoodiense Juez Dredd (Judge Dredd, Danny Cannon, 1995)² cuya narrativa, coetánea a la crisis finisecular del novecientos, atiende al discurso científico-social eugenésico, no solo recuperando sus características principales originarias decimonónicas, también las contemporáneas, de forma que enlaza en un juego intertextual la crisis política, económica y social de finales del siglo XX con los contextos cultuales de la centuria anterior.

Para acercar el análisis cultural de este tipo de narración fílmica, entendida como fuente histórica, al ámbito de los subtextos ideológicos que subyacen en ella, es necesario tener en cuenta que el objeto de estudio de esta investigación -el discurso ideológico conservador del relato Juez Dredd- se centra en el análisis del ideario científico-social eugenésico reflejado en este relato hollywoodiense de futuro distópico, influenciado por su contexto histórico-ideológico. La disciplina del nuevo historicismo resulta apropiada, en conjunción con los estudios culturales, por su interés en la investigación e interpretación de los textos de ficción destinados a las masas como transmisores de las ideas hegemónicas en la sociedad atendiendo a la temática del poder. "En cierto modo podría considerarse al nuevo historicismo como un método de análisis de texto de los estudios culturales [...] pero esta crítica no está tan interesada en las propiedades estéticas de la obra [...] como en su calidad de 'registro' del pasado" (Montes Doncel, 2004: 207-211).

El análisis neohistoricista atiende a la influencia y vinculación del contexto ideológico e histórico en la interpretación cultural de textos, los cuales forman parte "del campo ideológico en el que se configuran mutuamente las subjetividades individuales y las estructuras colectivas" (Montrose, 1998: 151). De manera que los individuos productores de textos artísticos son incapaces de inhibirse de su contexto histórico-ideológico (Fothergill-Payne, 1993: 377), por tanto, estos textos realizan una interpretación de la realidad creando otra, de manera que el contexto histórico real forma parte de la ficción.

La elección del discurso del relato finisecular del novecientos Juez Dredd responde a la recuperación que hace este texto fílmico de discursos eugenésicos que comenzaron a producirse durante el siglo XIX, difundidos por la cultura popular de masas de finales del ochocientos y principios del novecientos y de los que, en el contexto histórico-ideológico del relato cinematográfico objeto de estudio, aún pervivían interpretaciones eugenésicas que confluyeron en esta obra de distopía. Para el análisis de este trabajo de investigación se utiliza el método proporcionado por Aram Veeser, en su obra de 1989, The New Historicism, donde enunció los cinco axiomas que el nuevo historicismo se arrogaría como característicos y referenciales de su práctica, los cuales postulan que tanto los individuos como lo que producen están imbuidos y condicionados por el contexto histórico, ideológico y cultural. Se considera, de esta forma, a la producción cultural indisolublemente relacionada con su contexto histórico-ideológico (Hinojosa Picón, 2010: 42-47).

\footnotetext{
Producido por Hollywood Pictures, filial de The Walt Disney Company. Adaptación del cómic que comenzó a publicarse en 1977, Juez Dredd, de John Wagner y Carlos Ezquerra, en el segundo número de la revista británica $2000 A D$. "La corrupción y la violencia han sembrado el caos en la superpoblación de Mega-City Uno, un increíble paisaje urbano con torres de más de un kilómetro de altura e infinidad de vehículos aéreos que no cesan de cruzar sus calles. Para procurar el orden, existe un cuerpo capaz de aplicar tanto la justicia como el castigo al instante: son protectores de la ley, jurado y ejecutores, son... los Jueces. Y hay uno especialmente eficaz, radicalmente frío, temido por todos; es el Juez Dredd" (Cannon, 1995).
} 
La eugenesia, como ideología científico-social de origen decimonónico, pretende ser un método no solo preventivo de la degeneración de la sociedad, sino también promotor de su perfección gracias a la defensa de la hegemonía de los individuos que considera más aptos de la sociedad. El análisis de este trabajo de investigación es utilizado como un instrumento de conexión del discurso eugenésico decimonónico con la narración distópica Juez Dredd, de manera que la película se toma como texto donde se pueden localizar proyecciones de estas ideas científico-sociales en un entorno de ciencia ficción especulativa, partiendo de la premisa de que se puede diseñar un mapa ideológico de las mismas reflexiones -tanto en los discursos eugenésicos de finales del ochocientos como en el relato distópico hollywoodiense objeto de estudio- de las postrimerías del novecientos. Por tanto, Juez Dredd, al ser un producto cinematográfico perteneciente a la cultura popular de masas, será analizado como un discurso transmisor y perpetuador ${ }^{3}$ de las ideas hegemónicas en el que se proyectan los miedos e inquietudes coetáneas a su producción a finales del siglo XX.

En este contexto, el nuevo modelo de explotación económica de los productos hollywoodienses de masas que surgió a finales de la década de los años setenta revitalizó las producciones cinematográficas de ciencia ficción de tal forma que las convirtió en el género más rentable y popular. Además, la ciencia ficción cinematográfica volvió a manifestar las incertidumbres de la sociedad occidental coetánea en un contexto económico, político, social e ideológico de crisis finisecular, -especialmente en el relato distópico- creando un imaginario que se nutrió del pasado, de las consecuencias ideológicas conservadoras que partieron de las tensiones de la crisis de finales del ochocientos, para representar modelos sociales futuros, degradados y deshumanizados (La Polla, 2012: 1228-1232).

La ciencia ficción fue un género tan prolífico a nivel literario a finales del siglo XIX, como popular a nivel cinematográfico a finales del XX. Siendo un género donde la reflexión sobre el progreso científico y tecnológico es un elemento principal de sus relatos -dentro de las proyecciones que la ciencia ficción ${ }^{4}$ presenta sobre el futuro- la distopía se centra en realizar especulaciones extrapoladas y negativas, que parten de las preocupaciones del contexto histórico, político, social y económico en el que son concebidas estas tramas, sobre la evolución de la organización política y

\footnotetext{
Para Stuart Hall, los modos de perpetuidad, o "reproducción social" de la ideología dominante se entienden partiendo de que "en las condiciones de la producción capitalista también los medios del trabajo intelectual son expropiados por las clases dominantes. De ahí llegamos [...] al concepto de ideología dominante, de 'ideas dominantes' [...] Hay 'hegemonía' cuando las facciones de clase dominante no solo dominan, sino que dirigen: cuando no solo poseen el poder coercitivo, sino que se organizan activamente para conducir y obtener el consentimiento de las clases subordinadas. La 'hegemonía' depende, por tanto, de una combinación de fuerza y consentimiento. [...] La hegemonía no puede obtenerse solo en la esfera productiva y económica: debe organizarse al nivel del estado, la política y las superestructuras. [...] Esas estructuras de la 'hegemonía' trabajan mediante la ideología. [...] 'preservando la unidad ideológica de todo el bloque social' [...] Las clases dominantes [...] se esfuerzan, y en cierto grado lo consiguen, por enmarcar dentro de su alcance todas las definiciones de la realidad, atrayendo todas las alternativas a su horizonte de pensamiento. [...] El capitalismo reproduce las condiciones de producción 'a escala ampliada' y [...] ésta debe incluir la reproducción social." En esta noción de "reproducción social" se requiere "la actuación de todos los aparatos que aparentemente no tienen vinculación directa con la producción como tal. [...] La 'reproducción de la sumisión a la ideología dominante’ requiere las instituciones culturales, la iglesia, los medios de comunicación de masas, los aparatos políticos y la dirección global del estado" (Hall, 2010: 226-240).

4 As such, sf [science fiction] is a direct interaction with contemporary culture that lies at the nexus of technological, scientific, critical, and social thought in that it determines what we conceive of as possible in and for our future. Analyzing the collective desires and fears that determine such conceptions grounds us in the present and the social realities from which the science-fictional imagination starts (Schmeink, 2016: 19 y 20).
} 
social futura, donde los resultados del desarrollo de la ciencia y la tecnología pueden ser instrumentos intencionales o accidentales de opresión y degradación (Claeys, 2017: 284-290). Esta presentación de contextos alternativos no solo plantea ideas y/o comportamientos alternativos, sino que se puede llegar a presentar la destrucción de la sociedad e, incluso, de la humanidad. Estas imágenes colectivas de destrucción vienen azuzadas por los estragos y angustias de la vida urbana moderna, de manera que estas fantasías catastrofistas se manifiestan como una liberación de la modernidad, de forma que puede llegar a imaginar una sociedad tecnológicamente más avanzada en busca de una mayor eficiencia, pero simplificada y degenerada, en la que un innegable grado de deshumanización ha normalizado pensamientos y comportamientos que provocan, al menos, extrañamiento en la sociedad real en la que se producen estos relatos cinematográficos. Por tanto, las películas de ciencia ficción presentan negativas e hiperbólicas desviaciones imaginadas de la sociedad real hacia estadios involutivos, como alegorías de dilemas contemporáneos, que finalmente canalizan hacia contextos pacíficos, "pero las pesadillas colectivas no se pueden desvanecer demostrando que son, intelectual y moralmente, engañosas. Esta pesadilla -la reflejada, en varios tonos, en las películas de ciencia ficción- está demasiado próxima a nuestra realidad" (Sontag, 2015: 269-290).

Así, estas ficciones distópicas cinematográficas reflejan, de manera hiperbólica, las hipotéticas consecuencias negativas de la crisis, por lo que creaban una proyección conservadora mediante una imagen negativa que presentaba la posibilidad de degeneración o involución, en un futuro imaginado y aciago de la sociedad occidental real y en crisis, en la que fueron producidos estos relatos. De esta forma, los relatos distópicos de ambas centurias, como productos de la cultura popular de masas, funcionaron como transmisores de las ideas hegemónicas ya que forman parte de la ideología dominante y de su perpetuación (Montes Doncel, 2004: 207-211).

Con todo ello, en el relato Juez Dredd, como narración futurista distópica, se pueden distinguir tres características principales que también se encuentran presentes tanto en las distopías literarias de finales del siglo XIX y principios del XX, así como en las cinematográficas de finales del novecientos. Por una parte, atendiendo a la organización política, los relatos distópicos manifiestan el miedo a los estados autocráticos, totalitarios, por su tendencia a la homogeneización y sometimiento de los individuos de estas sociedades frente al poder. De manera que Mega-City I, la megaurbe futurista en la que se desarrolla el relato Juez Dredd, está gobernada de forma totalitaria por un Consejo de Jueces que acaparan todo el poder político y lo hacen cumplir de forma implacable e inhumana. Por otra, atendiendo a la organización económica de libre mercado, las distopías presentan las extremas desigualdades socioeconómicas de estas sociedades creadas tanto por el poder político autoritario como por el poder económico capitalista liberal (Martorell Campos, 2012: 275). Así, las clases bajas de Mega-City I viven tanto en los llamados bloques (blocks) como en las plantas más bajas de titánicos rascacielos, donde incluso la salubridad es menor, puesto que los niveles de contaminación son superiores a los de las plantas más elevadas, especialmente los lujosos áticos donde habitan las clases política, social y económicamente más alta, que se identifican también con el laboratorio de alta tecnología genética donde se llevan a cabo los experimentos de clonación (el Proyecto Jano) y con el edificio sede del Consejo de Jueces y lugar de instrucción de los nuevos jueces. Es decir, son los espacios desde donde se ejerce el control mediante la administración, el ejercicio del poder y el uso de la tecnología. Esta situación de 
dicotomía socioeconómica extrema lleva al enfrentamiento armado entre las bandas callejeras de los barrios bajos contra los jueces en la denominada Guerra de Bloques (Block War). Y, finalmente, estos relatos también relacionaban directamente el nivel de desarrollo científico-técnico e industrial con el grado de progreso de las proyectadas sociedades futuras, de manera que se planteaban los temores ante las posibles consecuencias negativas de la influencia de la tecnología y las características industriales tanto en la organización y las relaciones sociales, como en la biología humana (Hölscher, 2014: 146-156). De esta forma fracasan en sus fines, por una parte, el Proyecto Jano, una iniciativa eugenésica de ingeniería genética del Consejo de Jueces con la que pretende crear una élite socio-política formada por los individuos más aptos mediante la creación de clones que reúnan las consideradas mejores cualidades de cada miembro del Consejo ${ }^{5}$. Por otra, el uso de la robótica invasiva para poder subsanar la degeneración física y/o psicológica de los individuos pertenecientes a las clases más bajas, como es el caso de la progenie de familia Ángel (Angel), los cuales viven en la llamada Tierra Maldita (Cursed Earth), un desierto que se encuentra en las afueras de la tecnologizada megaciudad. La alteración biológica humana fallida tanto por la ingeniería genética como por la robótica suponen este reflejo del temor decimonónico a la degeneración de la especie y de la sociedad.

Teniendo en cuenta todo ello, ya desde finales del siglo XIX, en la producción literaria tanto europea -sobre todo británica-como estadounidense comenzó a destacar la proliferación de relatos de futuros aciagos auspiciados por el cambio de siglo, la crisis finisecular y las consecuencias de los cambios políticos, económicos, sociales y científico-técnicos del ochocientos. Así, los relatos distópicos decimonónicos y de principios del siglo XX presentaban la posible degradación y deshumanización de la sociedad occidental a causa de la industrialización, los desequilibrios socioeconómicos, y el desarrollo de la ciencia y la tecnología. Ante esta posible degradación, los Estados distópicos aplicaban medidas propuestas por la eugenesia para controlar y mejorar el conjunto de características heredadas de los individuos de una sociedad, consideradas por esta ideología decimonónica como positivas para la supervivencia y la orientación de la población hacia su perfección, erradicando así a los individuos menos aptos, los de las clases socioeconómicas inferiores, mediante el control restrictivo del crecimiento poblacional de estas clases (Claeys, 2017: 294-355).

Las corrientes de pensamiento científico-sociales decimonónicas contemporáneas a estos relatos partieron de los miedos y los peligros de la sociedades industriales y liberales, justificadora de la sociedad liberal burguesa, que reflejaba las consecuencias negativas de la industrialización urbana, potenciada por las reivindicaciones subversivas y la crisis económica de finales del siglo XIX. Estas preocupaciones provocaron el celo de seguridad y protección, llegando a la inhumanidad, de estas ideologías, tales como el neomaltusianismo, el darwinismo social, el degeneracionismo o el higienismo, entre las que cabe destacar la eugenesia (Dean, 2015: 166-174).

Francis Galton, primo de Charles Robert Darwin, es considerado el padre de la eugenesia, término que propuso en su obra Inquiries into Human Faculty and Its Development, de 1883 y que, influenciado por el maltusianismo, el darwinismo social

Para Thomas Douglas, "la imputación típica contra la eugenesia del perfeccionamiento [...] funciona cuando se refiere a las mejoras que comportan daños a terceros, caso de las aplicadas sobre la inteligencia, las habilidades físicas o la longevidad, las cuales beneficiarían a quienes las poseyeran en perjuicio de los demás" (Martorell Campos, 2017: 25). 
y el nacionalismo, definió en su artículo Eugenics: Its Definition, Scope, and Aims, de 1904: "la eugenesia es la ciencia que trata con todas las influencias que mejoran las cualidades innatas de una raza, así como aquellas que las desarrollan al máximo" (Galton, 1904: 1) ${ }^{6}$. Los eugenistas entendían que la progresiva degeneración de la población, cuestión que preocupaba tanto en Reino Unido como fuera de él ${ }^{7}$ era debida a que el crecimiento cuantitativo de las clases socioeconómicas más bajas, es decir, las entendidas como las menos aptas para perpetuar la sociedad, era muy superior al de las socioeconómicamente más altas, es decir, las consideradas como más aptas. Ante esta situación, se entendía que la mejor solución era controlar el crecimiento de la población mediante una selección artificial, siendo el talento un elemento primordial a tener en cuenta en la selección (Álvarez Peláez, 1990: 182). La eugenesia, por tanto, tiene como fin crear un futuro moldeando al ser humano gracias a la mejora cualitativa de las características heredadas en los individuos de una población (Dean, 2015: 173-174).

Por tanto, la reacción tanto del poder político-judicial del Consejo de Jueces, en el relato de finales del siglo XX Juez Dredd, así como de la eugenesia de finales del siglo XIX y principios del XX, no consistía únicamente en reforzar el adoctrinamiento, controlar y/o erradicar la subversión en la población, sino también mejorarla y evitar su degeneración o extinción. El Consejo de Jueces adopta los criterios eugenésicos que permiten la perpetuación de la estructura política, económica y social mediante la promoción de los más aptos, en detrimento de los menos aptos, una prevalencia a cargo del Estado, el cual debería utilizar la eugenesia como arma defensiva a la hora de realizar intervenciones preventivas ante posibles alteraciones del statu quo, como lo es la Guerra de Bloques. De manera que, en el reflejo negativo de un posible futuro de la sociedad occidental que presenta el relato Juez Dredd, la selección artificial propuesta por la eugenesia en la ciudad distópica Mega-City I responde a medidas propias de sociedades industrializadas que "traen consigo que el progreso se fosilice, que cunda por doquier la degeneración espiritual y que Occidente entero se rinda a un proceso disgenésico de decadencia conducente a la autodestrucción" (Martorell Campos, 2017: 22). En este sentido, la eugenesia, al ser algo propio de una sociedad industrial, "solo en una economía distinta a la economía de la ganancia se desintoxican los sueños de la intervención y de la reconstrucción orgánica” (Bloch, 2006: 30).

La eugenesia positiva está mucho más presente que la eugenesia negativa en la especulada sociedad futura de Juez Dredd: la eugenesia positiva propone potenciar la herencia de las consideradas mejores cualidades encontradas en los individuos de la sociedad. Dentro de las intervenciones eugenésicas positivas de este relato cinematográfico, encontramos el intento por evitar una degradación de la sociedad mediante los avances tecnológicos que proporciona la ingeniería genética y la robótica, sin tener en cuenta que las mejoras físicas tienen dos limitaciones:

a) Están limitadas por la biología. Los descubrimientos tecnobiológicos tienen un impacto en los individuos y en la sociedad, debido a que la estructura socioeconó-

6 "Eugenics is the science which deals with all influences that improve the inborn qualities of a race; also with those that develop them to the utmost advantage" (Galton, 1904: 1)

7 Durante el primer tercio del siglo XX, Galton fue considerado como uno de los primeros estudiosos de la genética de las poblaciones, estudios que se difundieron tanto por Reino Unido, gracias a Ronald Aylmer Fisher y John Burdon Sanderson Haldane, como por Estados Unidos, gracias a Sewall Green Wright (Ruiz Gutiérrez y Suárez y López Guazo, 2002: 101 y 102). 
mica influye colectivamente, de manera que, aunque solo se tuvieran como objetivo mejorar al individuo, estas intervenciones tienen repercusiones en la sociedad.

b) Las mejoras biológicas no son determinantes por sí solas, hay que tener en cuenta el factor ambiental. "Las contingentes y cambiantes circunstancias históricas donde moran los seres humanos continuarán moldeándolos y siendo moldeadas por ellos" (Martorell Campos, 2017: 25 y 29).

Por lo tanto, el resultado logrado por las intervenciones eugenésicas en Juez Dredd es el contrario al esperado: el fracaso de estas intervenciones eugenésicas puede deberse tanto a que, de la misma manera que Galton negaba la influencia del medio ambiente en la evolución de los individuos, no se estaría atendiendo a la variable ambiental, puesto que se estarían alterando "ciertas sustancias bioquímicas que al entrar en relación con otras y con el ambiente den resultados muy lejanos al esperado" (Sagols, 2009: 64); como a que "solo una sociedad no capitalista puede hacerse con el problema de la eugenesia con otros medios y cánones de la selección" (Bloch, 2006: 17). De esta forma, tanto los clones generados por la ingeniería genética del Proyecto Jano, como la progenie de la familia Ángel, cuya biología ha sido alterada mediante la robótica, son presentados como una degradación antinatural de la biología humana, de la que se cuestiona tanto su humanidad como su eficiencia, puesto que la eugenesia positiva pretende elevar al ser humano a un estadio evolutivo superior mejorando las cualidades que considera como positivas. En el caso del Proyecto Jano, la alta tecnología eugenésica se encuentra al servicio de la clase sociopolítica dominante, la cual tiene el temor de "un diagnóstico distópico según el cual la combinación de eugenesia y laissez faire amenaza con forjar una civilización totalitaria donde las selectas minorías mejoradas tutelarán a la mayoría no mejorada [...], sumando al ya de por sí determinante motor económico de la desigualdad el motor biológico" (Martorell Campos, 2017: 23 y 24).

De esta forma, respecto al uso de la alta tecnología -en concreto la ingeniería genética- Juez Dredd acoge en el discurso de la distopía características propias del ideario sociodarwinista, al buscar una mayor eficiencia, aunque sus fines sean eugenésicos, puesto que la intención es la de potenciar las cualidades que se consideran más beneficiosas para poder no solo superar el conflicto de subsistencia planteado en el relato, sino también alcanzar un perfeccionamiento de los individuos que les permita superar definitivamente esta crisis. De manera coetánea a este relato, las incertidumbres sobre el uso de la tecnología como mejoradora y, por tanto, alteradora de la biología humana a fínales del siglo XX fueron expuestas por los llamados bioconservadores, los cuales entendían que la intervención eugenésica mediante el uso de la tecnología para mejorar la eficiencia de la biología humana puede entenderse como un cuestionamiento de la naturaleza humana que la pone en peligro de ser, al menos, modificada.

Consideran que su uso más allá de la terapia constituye una amenaza a la dignidad humana, que pone en cuestión la propia existencia de una naturaleza humana, que se considera valiosa y digna de ser preservada, y proponen por consiguiente que su uso sea severamente restringido o sencillamente prohibido [...] Esta actitud de rechazo absoluto se acentúa aún más si cabe en el caso de la intervención eugenésica. (Rodríguez López, 2014: 16, 162) 
En el caso de la eugenesia negativa, esta pretende erradicar de los individuos, y por ende de la sociedad, los rasgos físicos y/o psicológicos considerados menos deseables, con la idea de crear una humanidad perfecta en un futuro no determinado, llegando a proponer actuaciones como el genocidio (Martorell Campos, 2017: 20 y 21). En el caso del uso de la tecnología robótica con el objetivo de reparar la degradación física y/o psicológica de los individuos degenerados y marginados, como lo son los vástagos de la familia Ángel, no tiene como finalidad la reparación del cuerpo, sino su mejora con el objetivo de eliminar las características degenerativas, "estos planes, por utópicos que sean, todavía proyectan en parte una sombra reaccionaria" (Bloch, 2006: 16). Aún cabe cuestionarse quiénes son los que seleccionan, bajo qué criterios y métodos, las mejores y las peores características, las que deben perpetuarse y las que deben desaparecer, con qué objetivos y cuál será el resultado (Martorell Campos, 2017: 25). De manera que la eugenesia negativa de la sociedad distópica de este relato cinematográfico de finales del novecientos sigue los criterios de la eugenesia de finales del siglo XIX y principios del XX, puesto que las víctimas de las medidas eugenésicas pertenecían a las clases socioeconómicas más bajas, aquellos individuos perjudicados, potencialmente opuestos al orden establecido y estigmatizados con la criminalización. Las clases socioeconómicas más altas se arropaban, de esta forma, al supuesto amparo de la teoría científica, eugenésica, como reacción al miedo ante una posible destrucción del orden social, económico y/o político. No solo preservar y mejorar las consideradas mejores cualidades de los individuos de la sociedad era objetivo de la eugenesia, también evitar la reproducción de los individuos considerados menos aptos. "Los altos estamentos de la sociedad, [...] querían que hombres y mujeres de moral similar, ética laboral, y salud física y mental prevaleciesen y que los trasgresores y dependientes del estado cesasen de reproducirse" (Reske, 2013: 17) ${ }^{8}$

Los individuos menos aptos, según los criterios eugenésicos, no están representados únicamente por la familia Ángel, que vive en la Tierra Maldita, fuera de la megaciudad; también por los miembros de las bandas callejeras enfrentadas con los Jueces, en la llamada Guerra de Bloques, dentro de Mega-City I. El Consejo de Jueces pretende derrotar y erradicar a la población subversiva: el genocidio como higiene racial, dentro de la aplicación más radical de la eugenesia negativa, atiende a la idea de que "el Estado deberá prevenir o extirpar los agentes patógenos. [...] La acción gubernamental eugenésica está orientada a separar, e incluso eliminar, las razas inferiores y a proteger la pureza de la raza superior y promocionar su desarrollo" (Segura del Pozo, 2009). De esta manera, no solo se evita la herencia y el contagio y de las características propias de individuos menos aptos, sino que, de esta forma, se acaba con ellos. La discriminación y marginalidad hacia la población subversiva puede atender a criterios biológicos y/o psicológicos, ideológicos y geográficos ${ }^{9}$. Desde el punto de vista geográfico, se produce una separación de la población subversiva de la no subversiva de manera que el primer grupo vive bien fuera de la ciudad artificial y altamente tecnologizada, es decir, en la naturaleza, la barbarie, como es el caso de la familia Ángel; bien en barrios bajos dentro de la urbe distópica, como es el caso

8 "The upper tiers of society, [...] they wanted men and women of similar morals, work ethic, and mental and physical health to prevail and transgressors and dependents on the state to stop reproducing" (Reske, 2013: 17).

9 "The interpretation of eugenics as a movement or set of values that stigmatized certain individuals and groups is itself allied to a belief that eugenics is inherently undesirable or unworthy. According to that belief, eugenics posed a threat not only to scientific credibility but to civilized society" (Ramsden, 2009: 854). 
de las bandas callejeras. Respecto a los criterios biológicos y/o psicológicos, caben destacar dos vertientes, bien la discriminación asociada a actos ilegales, bien el exterminio o genocidio del grupo de población subversivo. Cuando la marginación no es suficiente, se apela a medidas más drásticas, llegando al genocidio.

La separación geográfica en la que se encuentran las bandas criminales en Juez Dredd no es medida suficiente para contenerlos, por lo que el Estado propone medidas más drásticas: uno de los miembros del Consejo de Jueces que gobierna Mega-City I, el juez Griffin, propone endurecer las actuaciones que acaben con la Guerra de Bloques que las bandas callejeras mantienen entre ellas y también contra los jueces.

JUEZ GRIFFIN: ¡Juez presidente, la ciudad es presa del caos! Por el bien del orden social necesitamos riendas más ajustadas. El encarcelamiento no ha funcionado como disuasorio. ¡Digo que expandamos la ejecución para incluir delitos menores!

De esta forma no solo se pretende solucionar la violencia y el conflicto de los barrios bajos, sino también acabar con la escasez que padece la megaurbe debido al desequilibrio entre superpoblación y recursos insuficientes, lo que genera, a su vez, la preocupación en el Consejo de Jueces por evitar la degradación de la sociedad que pueda llevar a la desaparición del Estado y de la sociedad. De manera similar, a finales del siglo XIX y principios del XX, se entendía que "el interés de la especie, de la sangre, en definitiva, de la nación o de la patria estaba por encima del individuo y justificaba la intervención con el objetivo de atajar las causas de su degeneración" (Campos Marín, 1998: 345). El proyecto del juez Griffin tiene, por tanto, su origen en la cúpula política de la tecnologizada sociedad encapsulada en la distópica ciudad de Mega-City I que, respondiendo a los principios eugenésicos de finales del ochocientos y principios del novecientos, busca minimizar o eliminar a los individuos menos aptos (Segura del Pozo, 2009). Todo ello supone, además, la adopción de la interpretación eugenésica sobre el control legislativo del Estado, según la cual se debe sobreponer el fin eugenésico a los individuos. El freno de la degeneración defendido por el eugenista juez Griffin pretendía alcanzarse, aunque eso supusiera el sacrificio de individuos en aras del bien común. Todo ello estaría justificado, no solo por la consecución del fin, también por el coste social y económico que suponía la supervivencia y el mantenimiento de los considerados como indeseados, los menos aptos (Rodríguez López, 2014: 145-157). De esta forma el ex-juez Rico ironiza sobre la conveniencia de uno de los deberes del alcaide de la prisión, a pesar de encontrarse preso por sus crímenes.

JUEZ RICO: ¿Alimentando a estos parásitos aquí a expensas del público? ${ }^{10}$

Rico manifiesta la consideración eugenésica según la cual la protección o mantenimiento, por parte del Estado, de los individuos considerados menos aptos supondría una alteración contraproducente de la selección natural. De manera que, tanto Griffin como Rico, siguen los planteamientos eugenésicos que afirman la inconveniencia de la supervivencia de los menos aptos ya que, de esta forma, se estaría

10 JUDGE RICO: Feeding these parasites here at the public's expense? 
favoreciendo la degeneración de los individuos y, por tanto, de la sociedad, puesto que dicha degeneración se transmitiría mediante la herencia, entendida según el determinismo eugenésico. De forma que las soluciones eugenésicas propuestas por el juez Griffin y el resto del Consejo de Jueces conllevarían intervenciones tanto desde la eugenesia negativa, mediante la eliminación de los menos aptos, como desde la eugenesia positiva, gracias al Proyecto Jano, es decir, una selección artificial controlada con el objetivo de corregir la degradación y mejorar a la especie, y por ende a la sociedad (Sandín Domínguez, 2000: 38-47).

El determinismo al que estaría sometida la humanidad, según la eugenesia, podría ser derribado gracias a la selección artificial que busca una especie humana perfecta mediante el libre albedrío. Esto era debido a que la herencia ${ }^{11}$ era entendida de manera determinista. Francis Galton, siguiendo la misma línea del darwinismo social ${ }^{12}$, consideraba necesaria la mejora de la selección natural, que sería el "motor natural del proceso evolutivo", favoreciendo de manera artificial la herencia de las consideradas mejores características del ser humano. A lo que hay que sumar la concepción eugenésica de la herencia según la cual se transmiten de progenitores a la progenie, no solo las características físicas, también las psicológicas. El determinismo, causado por la herencia y la selección natural, provocaría una regresión de las consideradas mejores características. Del mismo modo, la selección artificial, especialmente la eugenesia positiva, basada en el libre albedrío, conllevaría el camino para alcanzar la perfección humana. Sin embargo, la eugenesia también es presentada en los relatos de distopía hollywoodienses como causantes de pérdida de libre albedrío.

Con todo ello, en la urbe Mega-City I del relato Juez Dredd, la élite sociopolítica formada por los jueces que salvaguardan e imponen la ley y el orden mantiene el concepto originario decimonónico de la eugenesia como "la aplicación de procedimientos de selección a través de métodos científicos y como fundamento para el diseño de una nueva élite imperante, una aristocracia del mérito y la capacidad, desarrollada a través de la combinación de los mejores"13 (Louçã, 2009: 678). El medio para alcanzar el ideal eugenésico de la humanidad perfecta es el Proyecto Jano, gracias al cual, individuos perfectos salvarían el decadente Estado político-judicial de Mega-City I, gobernado por el Consejo de Jueces, cuyo líder, el juez supremo Fargo, confiesa antes de morir al protagonista el intento de compensar el totalitarismo estatal con una nueva especie humana.

JUEZ FARGO: Una vez intentamos compensarlo: crear el juez perfecto. Lo llamábamos Jano. Hace cuatro décadas, se tomaron muestras de ADN de los miembros originales del consejo. Una fue elegida. La mía. La alteramos para realzar las mejores cualidades y filtrar las peores: debilidades, fragilidades. Te creamos a ti [...] Hubo otro infante creado en ese experimento, pero algo salió mal. Mutado genéticamente para ser el criminal perfecto ${ }^{14}$.

11 La herencia es entendida por los eugenistas como una simplificación de las leyes biológicas de Gregor Johann Mendel (Sandín Domínguez, 2000: 41-42).

12 Para Francis Galton, el estrato socioeconómico en el que se encuentren los individuos depende de "sus logros para escalar estratos sociales superiores.” Además, serían los más fuertes y capaces son los que sobreviven y transmiten este legado a su descendencia (Ruiz Gutiérrez y Suárez y López Guazo, 2002: 87-88).

13 "an application of selection procedures through scientific methods and as a rationale for the design of a new ruling elite, an aristocracy of merit and capacity, developed through the combination of the better" (Louçã, 2009: 678).

14 JUDGE FARGO: We once tried to compensate: Create the perfect judge. We called it Janus. Four decades ago, DNA samples were taken from the original Council. One was chosen. Mine. We altered it to enhance the best 
El Proyecto Jano, por tanto, supone la aplicación de una medida eugenésica que, al igual que las aplicadas a finales del siglo XIX y principios del XX, "implica un agente con un objetivo. [...] El agente era el estado y el objetivo la mejora de un colectivo, y lo que se consideraba mejor o deseable era definido por el agente promotor. [...] Suponía una violación de la libertad reproductiva de los individuos" (Rodríguez López, 2014: 162). De igual manera, encontramos en Juez Dredd eugenesia aplicada a las clases socioeconómicas más bajas: la tecnología robótica, aunque esta sea rudimentaria, que invade especialmente el cuerpo de uno de los vástagos de la familia Ángel, Malo (Mean Machine), personaje representante de la marginalidad, quien tiene una relación de oposición con el protagonista, el juez Joseph Dredd, personaje representante de la civilización. Dredd posee también una naturaleza biológica modificada, puesto que es fruto de un experimento genético, el Proyecto Jano, cuya finalidad es perpetuar el orden político-social al dar origen a una nueva élite de individuos más aptos. Ambos personajes, Malo y el juez Joseph Dredd, se enfrentan a muerte en lo que se puede interpretar como un enfrentamiento entre la civilización y la degradación, una selección natural apoyada en la tecnología; la robótica, como una tecnología anticuada, invasiva y degradadora, y la genética, como una tecnología más avanzada, menos invasiva y, a priori, más respetuosa con la naturaleza humana.

Sin embargo, el relato niega que el protagonista, prototipo de perfección humana, haya llegado a su estatus determinado por el Proyecto Jano, sino gracias al libre albedrío que posee, a pesar de ser fruto de un experimento genético eugenésico. Así, Rico, quien también nació del Proyecto Jano y considerado como hermano del heroico juez Dredd, por uno de sus padres biológicos e ideológicos, el juez supremo Fargo, es el villano. Es más, el criminal ex-juez Rico, contra el libre albedrío que representa su hermano, afirma el determinismo eugenésico ${ }^{15}$, cuando le presenta al protagonista su propio experimento de clonación eugenésico, con el que Rico pretende apoderarse del control totalitario de la ciudad, pero de manera unipersonal, gracias a un cuerpo de jueces de élite nacidos en base a su material genético.

RICO: Un gran e interminable suministro de perfección. Sabes, tenemos elección. Podemos quedarnos parados aquí y ahora, y crear toda una raza de imbéciles sometidos y llamarlos jueces. O podemos crear librepensadores. Les llamaremos humanos ${ }^{16 .}$

De esta forma, el determinismo biológico de Francis Galton se manifiesta en el Proyecto Jano, puesto que pretende una mejora que afecte tanto a la biología como

qualities and screen out the worst: Weaknesses, frailties. We created you. [...] There was another infant created in that experiment, but something went wrong. Genetically mutated to be the perfect criminal.

15 En este sentido, puede entenderse que "[las] elecciones que pueden perjudicar a los futuros hijos dotándoles de características que, si bien les hacen particularmente aptos para desarrollar un estilo de vida en concreto, les incapacitan, o dificultan extremadamente, para embarcarse en otros, con la consecuencia de que pueden verse abocados al tipo de vida que sus padres consideran el mejor simplemente por no tener opción. Estos niños serían menos libres de lo que lo hubieran sido de otro modo, de forma que aunque según sus padres hayan sido mejorados, desde su propio punto de vista, o desde el del resto de la sociedad, pueden estar peor. La ampliación de la libertad de los padres se habría comprado al precio de reducir la de los hijos" (Rodríguez López, 2014: 167).

16 RICO: One big endless supply of perfection. You know, we have a choice. We can stand here right now and create a whole race of brainwashed morons and call them judges. Or we can create some freethinking people. We'll call them human. 
a la humanidad de los individuos mediante la selección de las consideradas mejores cualidades y su perpetuación biológica, sin tener en cuenta el factor ambiental. "Propiedades como la inteligencia, la moralidad y la sociabilidad no dependen exclusivamente de lo biológico, y [...] su incremento es inviable sin las actuaciones ambientalistas adecuada" (Martorell Campos, 2017: 29). Esto se debe a que, aunque "llegaran a identificarse el gen de la inteligencia, de la belleza o de la honradez [...], esos genes por sí solos no serían determinantes de las cualidades intelectuales, estéticas o morales del individuo" (Camps, 2002: 58).

Además, la pervivencia del pensamiento eugenésico a finales del siglo XX influyó en la concepción de la tecnología Así, hasta la década de los años setenta del siglo $\mathrm{XX}$, estaba extendida la idea alienadora de la tecnología como estructuradora de la sociedad de masas y como un instrumento de domesticación capitalista. Desde la posmodernidad, la tecnología se pudo ver como un estímulo para el desarrollo de capacidades individuales, favorecedora de las posibilidades del hombre. Este cambio se inició a consecuencia de la crisis energética a principios de la década de los años setenta, tras la cual quedó demostrada la dependencia de la economía occidental de sus recursos energéticos ante la capacidad coercitiva de la OPEP (Organización de Países Exportadores de Petróleo).

Este hecho, muy posiblemente, fue el que produjo la inflexión en el cambio tecnológico, acelerando la denominada "lógica de la necesidad" que tuvo su respuesta en las nuevas tecnologías, que se distinguen fundamentalmente porque se basan en la información y en el conocimiento, sin generar apenas gasto energético ni consumo de materias primas de alto valor económico. (Colom Cañellas, 1997: 9)

De esta forma, en Juez Dredd la tecnología genética es origen tanto del villano, un asesino aspirante a autócrata, como del héroe, aunque este último no pretende desenmascarar el sistema autoritario, sino evitar una mayor degradación. De manera que el recogimiento de la eugenesia en este relato cinematográfico, influenciado por ideologías sociales conservadoras decimonónicas coetáneas, queda proyectado en las férreas y convencidas luchas de los protagonistas contra la degradación de una sociedad en crisis, los cuales se sacrifican por un bien mayor, por devolver un orden social perdido y degenerado o, al menos, evitar el avance de la degradación (Sklar, 2012, pp. 13791393). Además, en este relato distópico cinematográfico, perteneciente a la cultura popular de masas de finales del siglo XX, a pesar de poseer una visión posmoderna de la tecnología, se posicionan de una manera conservadora, no trascendente, respecto a los valores del pasado real. De esta forma, la tecnología no transforma la mente de los individuos de esta sociedad ficticia, sino que conduce a la autocracia y a reacciones conservadoras, en lugar de trascender gracias a la disposición que la sociedad tendría para investigar y desarrollar cualquier campo del conocimiento expresivo, creativo e intelectual.

Por tanto, en Mega-City I no hay una adaptación al cambio continuado, puesto que no es capaz ni de controlar estos cambios ni de aplicar nuevos métodos o medidas que puedan solucionar los problemas incipientes. Esta incapacidad es aún más llamativa si tenemos en cuenta que se trata de una sociedad distópica futura altamente tecnologizada, alejada de la naturaleza, la cual es relegada fuera de los límites geográficos urbanos. Así, el uso de las nuevas tecnologías y herramientas capacitaría la "estimulación y 
desarrollo funcional; con ello se posibilita la conexión entre las aportaciones de la neurociencia y el desarrollo de estilos cognitivos, en este caso de un estilo cognitivo sistémico y propio de la inteligencia creativa e innovadora. [...] En ella basculará el éxito o el fracaso de la humanidad" (Colom Cañellas, 1997: 8-18). Sin embargo, esto no ocurre en la sociedad imaginada del relato Juez Dredd, la cual no solo no trascienden el presente real, el contexto histórico en el que fue producido, sino que es conservadora puesto que colapsa, por lo que el relato propone conservar ad eternum los valores occidentales del presente real, puesto que sin ellos la sociedad efectiva correría el riesgo de desvirtuarse y degradarse, por lo que el colapso distópico podría estar más cerca.

Por tanto, la influencia de la eugenesia en el Estado político-judicial totalitario que gobierna Mega-City I no consistía únicamente en reforzar el control y/o la erradicación cuantitativa de los individuos considerados como menos aptos, también en mejorar cualitativamente la población favoreciendo a los más aptos. La intervención preventiva del Estado utilizando la eugenesia como arma defensiva a favor de la perpetuación de la estructura política y social, mediante la promoción de los más aptos, y en detrimento de los menos aptos, responde al temor decimonónico degeneracionista, del que se hizo eco la eugenesia, por la propagación de la degeneración y la subversión en la sociedad. Esta posible degradación, si no es controlada o combatida, podría llevar a un estadio involutivo que sería contraproducente tanto para la supervivencia individual como colectiva, es decir, de sociedad e, incluso, de la especie.

El relato distópico Juez Dredd refleja actuaciones eugenésicas que responden al temor por la degeneración individual y, como consecuencia, colectiva. De manera que, en la especulación negativa de un posible futuro de la sociedad occidental que presenta Juez Dredd, la selección artificial propuesta por el eugenésico Consejo de Jueces en Mega-City I responde a medias propias de sociedades industrializadas que "traen consigo que el progreso se fosilice, que cunda por doquier la degeneración espiritual y que Occidente entero se rinda a un proceso disgenésico de decadencia conducente a la autodestrucción" (Martorell Campos, 2017: 22). En este sentido, la eugenesia, al ser algo propio de una sociedad industrial, "solo en una economía distinta a la economía de la ganancia se desintoxican los sueños de la intervención y de la reconstrucción orgánica" (Bloch, 2006: 30).

Tanto la eugenesia positiva como la negativa que se encuentran en este relato distópico hollywoodiense de finales del siglo XX responden a los principios eugenésicos decimonónicos en los que la degeneración individual y, por tanto, social, junto al determinismo de la herencia, propician una selección artificial de las consideradas mejores características a perpetuar, lo que supone la eliminación de los individuos considerados menos aptos, los pertenecientes a las clases socioeconómicas más bajas, a los cuales se les impone una inhumana aplicación de las medidas eugenésicas que permiten una perpetuación de la estructura política y social. Además, estas medidas y su relación con el avance científico-técnico resaltarán igualmente las preocupaciones eugenésicas coetáneas de finales del novecientos.

\section{Bibliografía}

Álvarez Peláez, R. (1990). "La mujer española y el control de natalidad en los comienzos del siglo XX". Asclepio. Revista de Historia de La Medicina y de La Ciencia, vol. 42, 175-201. 
Bloch, E. (2006). El principio esperanza. Madrid: Trotta.

Campos Marín, R. J. (1998). "La teoría de la degeneración y la medicina social en España en el cambio de siglo". Llull. Revista de La Sociedad Española de Historia de Las Ciencias y de Las Técnicas, vol. 21, núm. 41, 333-356.

Camps, V. (2002). “¿Qué hay de malo en la eugenesia?” Isegoría. Revista de Filosofia Moral y Política, núm. 27, 55-71. DOI: https://doi.org/http://dx.doi.org/10.3989/isegoria.2002.i27.554

Cannon, D. (1995). Juez Dredd. [Blu-ray]. Estados Unidos: Laurenfilm, S.A.

Claeys, G. (2017). Dystopia: A Natural History. Nueva York: Oxford University Press.

Colom Cañellas, A. J. (1997). "La regionalización de la educación como tecnología cognitiva virtual”. Teoría de La Educación, vol. 9, 7-19. DOI: https://doi.org/10.14201

Dean, M. (2015). "El efecto Malthus. Población y gobierno liberal de la vida". Sociología Histórica. Revista de Investigación Acerca de La Dimensión Histórica de Los Fenómenos Sociales, núm. 5, 165-193.

Fothergill-Payne, L. (1993). “Ars histórica y neo-historicismo: ¿Qué hay de nuevo?” Estado actual de los estudios sobre el Siglo de Oro: Actas del II Congreso Internacional de Hispanistas del Siglo de Oro, vol. 1, 375-378. Salamanca: Universidad de Salamanca. Recuperado de https://cvc.cervantes.es/literatura/aiso/pdf/02/aiso_2_1_037.pdf (Fecha de acceso: 25/01/2019).

Galton, F. (1883). Inquiries into Human Faculty and Its Development. Londres: Macmillan and Co. Recuperado de https://archive.org/details/inquiriesintohu00galtgoog (Fecha de acceso: 28/02/2019).

Galton, F. (1904). "Eugenics: Its Definition, Scope, and Aims". The American Journal of Sociology, vol. 10, núm. 1, 1-25. Recuperado de http://www.jstor.org/stable/2762125 (Fecha de acceso: 03/03/2019).

Hall, S. (2010). Sin garantías. Trayectorias y problemáticas en estudios culturales. Popayán: Envión editores.

Harris, P. y Ezquerra, C. (1977). “Judge Dredd. 2000 A.D.”, vol. 2, núm. 2. Recuperado de http://www.2000ad.org/?zone=thrill\&page=thrillviewer\&choice=whitey\&thrillpage $=1$ (Fecha de acceso: 16/02/2019).

Hinojosa Picón, O. (2010). Ficción histórica y realidad literaria. Análisis neohistoricista del socialismo en la obra de Monika Maron. Berna, Berlín, Bruselas, Frankfurt, Nueva York, Oxford y Viena: Peter Lang.

Hölscher, L. (2014). El descubrimiento del futuro. Madrid: Siglo XXI.

La Polla, F. (2012). "La ciencia ficción”. En Gian Piero Brunetta (dir.), Historia mundial del cine. Estados Unidos, vol. I.II. Madrid: Akal, 1221-1232.

Louçã, F. (2009). "Emancipation Through Interaction - How Eugenics and Statistics Converged and Diverged". Journal of the History of Biology, vol. 42, núm. 4, 649-684.

Martorell Campos, F. (2017). "Amplificando técnicamente la virtud. Utopía y moral enhancement”. Prometeica, núm. 14, 16-33. DOI: https://doi.org/https://doi.org/10.24316/ prometeica.v0i14.170

Martorell Campos, F. (2012). "Notas sobre dominación y temporalidad en el contexto postmoderno a propósito de la distopía". Astrolabio. Revista Internacional de Filosofía, núm. 13, 274-286.

Montes Doncel, R. E. (2004). "De nuevas sobre el Nuevo Historicismo". Anuario de Estudios Filológicos, vol. 27, 207-219.

Montrose, L. A. (1998). "Los nuevos historicismos". En Penedo, A. y Pontón, G- (Eds.), Nuevo Historicismo. Compilación de textos y bibliografía. Madrid: Arco/Libros, 151192. 
Ramsden, E. (2009). "Confronting the Stigma of Eugenics: Genetics, Demography and the Problems of Population". Social Studies of Science, vol. 39, núm. 6, 853-884. DOI: https://doi.org/https://doi.org/10.1177/0306312709335406

Reske, P. E. (2013). “Policing the 'Wayward Woman': Eugenics in Wisconsin's Involuntary Sterilization Program”. The Wisconsin Magazine of History, vol. 97, núm. 1, 14-27.

Rodríguez López, B. (2014). “¿Qué hay de positivo en la eugenesia positiva?” Anuario de La Facultad de Derecho de La Universidad Autónoma de Madrid, núm. 18, 141-170.

Ruiz Gutiérrez, R. y Suárez y López Guazo, L. (2002). "Eugenesia, herencia, selección y biometría en la obra de Francis Galton". Llull. Revista de La Sociedad Española de Historia de Las Ciencias y de Las Técnicas, vol. 25, núm. 52, 85-108.

Sagols, L. (2009). “QQué aporta la eugenesia de diseño ético a la ética?” En López de la Vieja, M.T. (Ed.), Ensayos sobre bioética. Salamanca: Universidad de Salamanca, 59-68.

Sandín Domínguez, M. (2000). "Sobre una redundancia: El darwinismo social”. Asclepio. Revista de Historia de La Medicina y de La Ciencia, vol. 52, núm. 2, 27-50. DOI: https:// doi.org/https://doi.org/10.3989/asclepio.2000.v52.i2

Schmeink, L. (2016). "Dystopia, Science Fiction, Posthumanism, and Liquid Modernity". En Seed, D. (ed.), Biopunk Dystopias. Genetic Engineering, Society and Science Fiction. Liverpool: Liverpool University Press, 18-70.

Segura del Pozo, J. (2009). "Salud Pública y Biopolítica: Degeneracionismo y Eugenesia". Recuperado de http://www.madrimasd.org/blogs/salud_publica/2009/01/14/111133 (Fecha de acceso: 8/3/2019).

Sklar, R. (2012). "El cine de los años ochenta". En Gian Piero Brunetta (dir.), Historia mundial del cine. Estados Unidos, vol. I.II. Madrid: Akal, 1379-1393.

Sontag, S. (2015). "La imaginación del desastre". En Major, A. (ed.), Contra la interpretación y otros ensayos. Barcelona: Debolsillo, 269-290.

Veeser, H. A. (ed.). (1989). The New Historicism. Nueva York: Routledge, Chapman and Hall, Inc. 